\title{
¿QUIÉN ES MALTE LAURIDS BRIGGE?
}

\section{Susana ARROYO REDONDO}

\author{
Universidad de Alcalá \\ su_arroyo@hotmail.com
}

Resumen: El artículo profundiza en los aspectos autobiográficos y las renovaciones formales de Los apuntes de Malte Laurids Brigge, de Rainer María Rilke, que más han influido en la creación del Yo novelístico contemporáneo.

Abstract: This article studies in depth the autobiographical aspects and the formal innovations which make of The Notebooks of Malte Laurids Brigge, by Rainer Maria Rilke, the very promoter of the contemporary «I» in the novel.

Palabras clave: Rilke. Malte. Novela. Autobiografía. París.

Key Words: Rilke. Malte. Novel. Autobiography. Paris. 


\section{INTRODUCCIÓN}

Los apuntes de Malte Laurids Brigge han sido considerados la primera novela del siglo XX o al menos la obra que marca el paso del género novelístico decimonónico a una nueva era. Y es curioso que una obra que no se presenta a sí misma como novela, sino como unos meros apuntes desordenados, que renuncia a un argumento tradicional y a un desarrollo coherente, sea considerada precisamente como origen de la novela moderna.

Efectivamente, esta novela - pues novela se considerará a esta obra en las siguientes páginas - inaugura una nueva forma de afrontar en el texto el problema de las relaciones entre el Yo y la realidad exterior. Generalizando, se puede decir que la novela del XVIII plantea por primera vez la necesidad de construir desde dentro de la narración la personalidad de un personaje con un nombre propio (llámese Tom Jones, Tristam Shandy o Robinson Crusoe) que, a diferencia del de los héroes clásicos, no significa nada. La novela del XIX profundizó en la psicología de los personajes y en la insatisfacción que la sociedad provoca en el hombre, pero pretendió definir el Yo del protagonista como el de una personalidad representativa o un tipo social. Y así, el Malte se presenta como un punto de inflexión en la evolución de la novela del Yo, pues pretende, por primera vez, crear una conciencia que desenmascare la sociedad y que se desenmascare a sí misma; sin que el desarrollo de una personalidad tenga que excusarse en un argumento banal y supuestamente representativo.

Pero precisamente todo esto hace de la obra de Rilke un texto tan ambiguo, tan fragmentado, que es difícil incluirlo dentro de cualquier género, incluso de uno tan amplio e indefinido como el de la novela. La forma del diario propicia que el Yo se apodere de la historia hasta el punto de que lo exterior parece desaparecer. Incluso el ligero argumento se desvanece en una vuelta al pasado que se pierde en el mito. Y los personajes que intervienen no parecen reales, pues no son descritos ni física ni psicológicamente, y hasta podrían ser fantasmas imaginados por el protagonista.

Pero si la peculiar obra de Rilke todavía tiene que demostrar su categoría de novela es porque hasta ahora parece habérsela relacionado demasiado con la tradicional novela decimonónica, aunque, en realidad, tiene mucho más que ver con las actuales novelas que mezclan narración, ensayo y memorias. Efectivamente, su innovadora investigación del Yo necesitó una arquitectura formal igualmente revolucionaria y a veces cercana a la lírica, el género de la intimidad por antonomasia. 
En estas páginas se analizará precisamente la arriesgada innovación formal de Rilke y cómo su texto, a pesar de su acercamiento a la poesía y de su revolucionario fragmentarismo, es efectivamente una novela. En primer lugar, se plantearán los antecedentes de la novela, insistiendo en lo que de autobiográfico, o de mezcla de vida y ficción, puede esconderse en las páginas del Malte. En segundo lugar, se estudiará la innovadora forma que caracteriza a esta peculiar obra y cuáles son los avances formales que permiten situarla en el género novelesco. Y por último, se planteará una interpretación del argumento a partir de las peculiaridades formales del texto.

\section{RILKE Y MALTE EN PARÍS}

En febrero de 1904 ciertas secciones de cartas enviadas desde París por el joven Rilke a su antigua amante rusa, Lou Andreas Salomé, empezaron a dar cuerpo a una novela que en principio se llamaría Diario de mi otro yo. El protagonista sería un joven danés de origen aristocrático que llega a la capital francesa y se siente superado por la vorágine de la ciudad. Si se tienen todos estos hechos en cuenta, parece evidente que hay un fondo autobiográfico en esta obra escrita por un joven Rilke que, precisamente, había llegado a París en 1902 para conocer y acabar trabajando como secretario del escultor Rodin. Como Malte, Rilke siempre había abogado por la necesidad de estar en soledad, por una vida libre en la naturaleza; en París se sentía ofendido por la fealdad del paisaje, abatido por la despersonalización de la masa. Así, las primeras páginas de los Apuntes no parecen sólo ser autobiográficas en cuanto a lo que respecta a la fecha y el lugar, sino también en el sentimiento de odio hacia París. En una de las epístolas del poeta editadas por Holthusen (1968: 110) Rilke dice a su mujer, Clara, el 11 de noviembre de 1902:

Yo no puedo expresar lo antipático que a mí me resulta aquí todo, ni describir la instintiva repulsa con que yo me muevo aquí.

En la ciudad, el poeta praguense sufría una soledad agónica que lo consumía, pero que, paradójicamente, también le resultaba altamente productiva; de hecho, durante doce años París se convirtió en el centro geográfico de su vida y cada vez que se alejaba de ella, volvía rápidamente. ¿Por qué? Puede que París aportara a Rilke un tipo de soledad tal vez más sincera que la que se puede sentir en mitad de la naturaleza: la que se llega a experimentar entre la multitud, la soledad que es un estado del alma. Y es que fue en el París 
de principios del siglo XX donde se gestó la vida urbana moderna, con su carga de soledad, multitud, encuentros súbitos e inolvidables, azar, vagabundos y viajeros. Y puesto que la angustia que causa la ciudad pone a prueba la excelencia de las ideas ilustradas y los corazones románticos, también fue en ese París donde se gestó la obra de Cézanne, Baudelaire y Flaubert - admirados tanto por Rilke como por Malte - que a lo largo de los Apuntes serán mencionados como modelos a seguir en el camino de exposición a lo real para extraer poesía de cualquier objeto. Así lo reconoce el propio Rilke en la siguiente carta recogida en la antología editada por F. Bermúdez Cañete (1987: 91):

Seguramente te acuerdas... del pasaje de «Los Apuntes de Malte Laurids Brigge», donde se trata de Baudelaire y de su poema «La carroña». He llegado a pensar que sin ese poema, la evolución hacia el lenguaje objetivo que creemos reconocer ahora en Cézanne nunca hubiera podido empezar; era necesario que antes existiera así, despiadado. Antes era necesario que la mirada del arte se hubiera esforzado hasta tal punto que viera también en lo terrible, y en lo que sólo parece repugnante [...]. No se le permite al creador $n i$ seleccionar ni apartarse de ninguna cosa existente; un solo rechazo, en cualquier momento, le priva del estado de gracia, le vuelve absolutamente culpable.

Efectivamente, las experiencias de Rilke en la capital francesa son fundamentales para entender la forma y el contenido del Malte. No sólo porque lo autobiográfico de algunas escenas explica los pasajes en forma de diario o incluso de correspondencia privada, sino porque conocer a Rodin le inspiró a Rilke la noción de trabajo continuo sobre la palabra, como si de una cosa se tratara. En París concibió el joven poeta la idea de un lenguaje objetivo, es decir, de crear a partir de todo lo real un lenguaje que sea sólido y simultáneo como la piedra del escultor. Así intentó plasmarlo en sus Nuevos Poemas (1907-1908) y luego, como se tratará de demostrar en las siguientes páginas, volvió a ensayar esta cosificación de la lengua en su Malte, ahora en prosa.

En definitiva, parece necesario tener en cuenta las experiencias del autor en París para entender las de su personaje; no porque Malte sea un alter ego idealizado de Rilke - que también es posible - , sino porque ambos asumieron los horrores de la metrópolis para sentarse a escribir y hacer de todo ello una introspección personal. La importancia personal que Rilke concedía a esta novela es capital y así se lo dijo a su querida Lou Andreas-Salomé en la siguiente carta, escrita el 28 de diciembre de 1911, poco después de que terminara su Malte: 
No necesito respuestas a mis libros, eso lo sabes, pero ahora considero necesario, de corazón, saber qué impresión te ha hecho el libro [...]. Pero nadie más que tú, querida Lou, puede distinguir y demostrar si se parece a mí y hasta qué punto. Si él, que en parte está hecho de mis peligros, sucumbe en ellos, en cierta medida para ahorrarme a mí el hundimiento, o si con estos apuntes he entrado en la corriente que me arrastraba y arrastra al otro lado [...] (Ibídem, 102-104).

\section{3. ¿UNA NOVELA?}

Como ya se ha comentado en la introducción, esta obra de Rilke se resiste a ser asignada a un género concreto por lo inclasificable de su forma. Normalmente se dice que es una novela escrita en primera persona, pero ya desde el título se anuncia que estas páginas parecen más un montón de papeles desordenados, unos apuntes o unos cuadernos. Y es que la falta de unidad de los pasajes, de una trama en torno a la cual se desarrollen los acontecimientos y de unos personajes sólidos causan una dispersión total. Además, la obra también aparenta ser una larga epístola y, de hecho, las primeras páginas tienen la forma de una carta. Sin embargo, el lector sabe que Malte no tiene a nadie en el mundo a quien enviar esta carta, así que sus páginas también podrían ser un diario que el joven escribe para sí mismo, lo cual explicaría la inconexión de los párrafos. Finalmente, la falta de anécdota exterior y la profundidad con la que se bucea en la mente del narrador y protagonista podría definirse incluso como pensamiento narrado.

Dadas todas estas ambigüedades, se podría considerar al Malte como algo parecido a una novela del Yo, un tipo de texto fronterizo entre la narración, el diario y la autobiografía. Esta clase de obras explotaría el problema que ha ocupado incansablemente a la novela desde hace ya dos siglos: el enfrentamiento del Yo con el mundo exterior. Y es que, si en la Antigüedad el mundo estaba hecho según las dimensiones del hombre, a partir del siglo XVIII se abre una brecha entre el universo interior y el exterior que nunca volverá a cerrarse. La realidad ya no es capaz de gratificar las expectativas de los personajes, pues a las ansias poéticas del alma se oponen las condiciones prosaicas de un mundo burgués. Entonces, el novelista se enfrenta al hecho de que, si bien hay distintos medios para representar el mundo real y la sociedad, se necesitan nuevas fórmulas para plasmar la conciencia interior. Mostrar el desarrollo personal a través de una historia representativa de cierto tipo social ya no es suficiente para representar la complejidad del Yo moderno: no hay forma de expresar lo interior a través de lo exterior. En este 
sentido, Los apuntes de Malte Laurids Brigge, tienen poco que ver con otras novelas anteriores y mucho con otras que fueron escritas mucho después, por ejemplo La nausea de Sartre (1938) y El extranjero de Camus (1946), pues todas ellas vienen a renovar los medios expresivos de la novela del $\mathrm{Yo}^{1}$.

Así, Rilke pronto debió de comprender que la novela que quería escribir no tenía nada que ver con acciones o con el orden cronológico tradicional de una biografía, es decir, no tenía nada que ver con una aproximación externa a la experiencia interior. Para acercarse al Yo, Rilke abandona la descripción de toda acción externa, aunque eso suponga renunciar a la unidad narrativa que hace artísticamente posible la novela tradicional. Este proyecto implica abandonar el argumento para concentrarse en las impresiones del narrador sin tener que traducir sus estados interiores en el desarrollo de una trama convencional. Por otra parte, no hay personajes estables, todos parecen salidos de la imaginación de Malte porque siempre son descritos desde su cambiante y poco fiable punto de vista. Se renuncia, también, a toda objetividad exterior: la historia sucede principalmente en la mente del protagonista y en las pocas veces que describe la vida real se niega a mirar el mundo desde otra perspectiva que no sea la interior.

Rilke intuye que la personalidad consciente es sólo una pequeña parcela del Yo, cuya base se expande indefinidamente, independiente del tiempo y del espacio. Si se lograra experimentar el Yo en toda su extensión se experimentaría la simultaneidad, todo lo que normalmente sólo se vive como una secuencia de acontecimientos. Mientras que la novela tradicional sólo refleja la personalidad consciente, Rilke se propone atrapar la simultaneidad en un personaje que experimente su pasado y su futuro de la misma forma que su presente.

Esta experiencia simultánea y casi física de lo artístico es la Cosa, un objeto sólido construido con el lenguaje objetivo del que Rilke hablaba en la carta a Clara antes citada. Sus Nuevos poemas son una obra hasta cierto punto impersonal porque se abomina del subjetivismo para crear poemas que sean también cosas, pero parece que el Malte es más bien un intento de mezclar la subjetividad (en el tema y los puntos de vista) y la solidez (de un

\footnotetext{
1 Esta renovación se ha relacionado habitualmente con el fondo existencialista que rodeará a la voz de la primera persona narrativa en las novelas superadoras del realismo. Sin embargo, como se verá más adelante, no son los hechos extralingüísticos sino los formales los que dotan al Malte de su revolucionaria originalidad; no es el eco filosófico de la voz de Malte lo que coloca a esta obra casi fuera del género novelesco y cerca del diario, la carta o el ensayo, sino su disposición disgresiva, simultánea, antibiográfica y fragmentaria.
} 
lenguaje nuevo y firme como una cosa $)^{2}$. Esta concepción, aprendida de Rodin, anima a Rilke a abandonar el desarrollo temporal típico de la novela para crear pequeñas escenas fragmentarias que deben interpretarse de forma total $^{3}$. Así, los pasajes de la novela no proponen un avance en la historia sino que son pasajes de gran intensidad lírica y autosuficiente que pueden ser considerados casi como prosa poética.

Esta experimental prosa poética, destinada a romper la tiranía formal de la poesía clasicista, se gestó a lo largo de todo el romanticismo pero adoptó su forma definitiva en los Pequeños poemas en prosa (Petits Poèmes en Prose) que Ch. Baudelaire publicó en 1869. En este libro, muy admirado por Rilke, se definió una nueva forma lírica necesariamente fragmentaria y de plena inspiración urbana. Así lo declara el poeta francés en la dedicatoria de aquella obra:

¿Quién de nosotros no ha soñado, en sus días ambiciosos, con el milagro de una prosa poética, musical, sin ritmo ni rima, lo suficientemente flexible y dura como para adaptarse a los movimientos líricos del alma, a las ondulaciones del ensueño y a los sobresaltos de la conciencia? Este ideal obsesivo nace, principalmente, de la frecuente visita a las ciudades enormes, del cruce de sus innumerables relaciones ${ }^{4}$.

Esta prosa fragmentada tiene, además, la ventaja de reflejar perfectamente la identidad fraccionada del protagonista, su psicología dividida a causa del contacto con la ciudad; una situación que Malte experimenta incluso de forma física en el pasaje de la mano animada o en el de los rostros con múltiples máscaras.

Así, Rilke crea pequeños momentos privilegiados de emoción lírica a imagen de Baudelaire y del noruego Sibjon Obstfelder - quien también creaba obras de carácter misceláneo, desordenado-; pero a diferencia de su maestro francés, Rilke pretende integrar sus fragmentos de prosa poética en la estructura superior de una novela. Así, la visión simultánea de toda la obra podría transmitir la solidez de una Cosa. Pero lo que es válido para la poesía presenta problemas formales en la prosa. A saber, una estructura fragmen-

\footnotetext{
${ }^{2}$ En este sentido, Malte se puede considerar una continuación en prosa del intento fallido de los Nuevos poemas por conseguir una poesía cosificada.

${ }^{3}$ Una idea tal vez surgida en las primeras visitas de Rilke al estudio de Rodin, donde aquél quedó fascinado por la abundancia de enormes fragmentos de estatuas que parecían más acabados que si estuvieran formando parte de una composición completa.

${ }^{4}$ Cito por la edición española de J. A. Millán Alba (1986: 46).
} 
taria, por más que quiera ser captada de un modo simultáneo, presenta un grave problema de unidad novelesca. Es decir, la disposición aparentemente caótica de unos pasajes sin hilo conductor definido no conforma una novela, sólo un libro de estampas.

Por eso, Rilke elabora una obra con una unidad diferente a la de la novela tradicional (argumento, personajes, tiempo...), basada en primer lugar en la misma esencia de la prosa. Este tipo de escritura presenta una unidad mayor a la de la poesía por la existencia de un protagonista, identificado con nombres y apellidos, ya desde el mismo título, y por la repetición de temas. Además, la presencia unificadora del personaje principal aleja al texto de la desconectada estructura baudelaireana para acercarlo al diario íntimo; una forma que no sólo justifica el fragmentarismo del texto, sino que disculpa también los monólogos disgresivos que interrumpen la narración.

Pero la unidad está sobre todo garantizada por la totalidad de la experiencia que se expresa en la novela: Malte, convencido de la necesidad del credo de aceptación expresado en La Charonne, quiere afirmar y afrontar todas sus experiencias, incluso las más negativas. Además, otro elemento de conexión lo constituye la propia conciencia de Malte, que está embebida en su experiencia inmediata desde París, y desde ese mismo enclave temporal y espacial observará siempre su pasado. Por otra parte, Rilke comprende que la presencia del autor es también unificadora porque es una conciencia que abarca toda la acción en sí misma. Esta presencia trasciende objetivamente todos los fragmentos de la narración, todos los puntos de vista y la conciencia de los personajes. Si se considera a Malte como alter ego de Rilke, entonces se podría considerar que el autor ejerce ese papel englobador.

Por su puesto, este intento de novela horizontal o simultánea, de crear un cuadro o una Cosa a través de las palabras choca inevitablemente con la naturaleza de la novela y del mismo lenguaje, que sólo puede existir en el tiempo. Puede que esto también contribuyera al fracaso de Malte como personaje, de lo cual, como se verá en el siguiente apartado, hablaría después Rilke en su correspondencia. Además, el intento de crear un texto-cosa choca también con la estructura tradicional de la novela: Rilke crea un texto descentrado, sin un desarrollo argumental, ni cronológico, ni psicológico evidente pero ni siquiera él puede renunciar a cierto desarrollo de la historia y se hace evidente que el joven que habla en las primeras páginas nada tiene que ver con el que se diluye en las últimas. Y, en conclusión, si estos Apuntes no tienen mucho que ver con la novela nuclear clásica, sí están emparentados con la novela horizontal, mezcla de diario y narración, que se escribirá a finales 
del siglo Xx. Por lo tanto, se puede considerar que si bien Los apuntes de Malte Laurids Brigge no son una novela tradicional, tampoco puede excluírselos de este género sólo porque Rilke cometiera el atrevimiento de adelantarse varias décadas a las corrientes renovadoras del género de la novela 5 .

\section{UNA NOVELA SOBRE EL YO}

Una vez analizada la forma de esta extraña novela, se puede proceder a interpretar el deslavazado argumento que allí se trata. En líneas generales, se relata la llegada de un joven poeta a la capital francesa y cómo éste siente la necesidad de ponerse a escribir todo lo que allí ve para recuperar un Yo que se le escapa; para ello, el joven se sumerge primero en los recuerdos de su infancia, luego llegará a rememorar un pasado histórico cada vez más lejano y confuso, y finalmente llegará a diluirse en un pasado mítico. Es decir, al contrario que en la Bildungsroman, donde el héroe pasa por ciertas pruebas hasta reafirmar su posición en el mundo exterior, Malte se irá transformando de forma interior, desapareciendo hasta llegar a una situación incierta, cerca del mito o del fantasma. En lo que respecta a la evolución temática, el libro también puede dividirse en dos ejes simbólicos complementarios: primero, la obsesión por la muerte (especialmente la muerte en masa, industrial y solitaria de la ciudad), y después, el amor (entendido como amor intransitivo y que no exige ninguna adhesión).

En las siguientes páginas se explica más en detalle esta compleja evolución, que según el propio Rilke declara en una carta a Lotte Hepner de 1915 (Bermúdez Cañete, 1987: 122-127), debe ser interpretada como el relato de un fracaso:

Lo que en «Malte Laurids Brigge» está expresamente dicho [...], es propiamente sólo esto, con todos los medios y siempre otra vez desde el comienzo y según todas las pruebas esto: esto, ¿cómo es posible vivir, cuando los elementos de esta vida son completamente incomprensibles para nosotros? Si somos siempre insuficientes en el amor, inseguros en las decisiones e incapaces frente a la muerte, ¿cómo es posible existir?

\footnotetext{
5 «Rilke cometió el error de acortar mucho y de innovar demasiado pronto. La crítica ha reprochado a Malte (mientras que lo acepta como algo corriente en las novelas actuales) que sea un poeta demasiado sensible a su época, que se anticipe a la historia, incluida la del género novelesco. Soñando primero con dotar a su héroe de una biografía, renuncia a contar la historia desde su nacimiento a su muerte, a su formación social, para retratarlo simultáneamente como joven en París y como niño en Dinamarca» (Bernard Lortholary, 1993: 40. Traducción propia).
} 


\subsection{París: aprender a ver y tener miedo}

La novela arranca con un argumento bastante preciso: un joven danés de origen aristocrático llega a París y cuenta en primera persona cómo se siente abrumado por la metrópolis, por su deshumanización, por la multiplicidad de los rostros que la pueblan. Sus experiencias en París, un lugar en el que se viene a morir de forma despersonalizada, motivan una inextricable mezcla de sentimientos expresada en sus reflexiones: Aprendo a ver (porque ha accedido a una realidad diferente y altamente productiva) y Tengo miedo (porque este mundo es deshumanizado y aterrador). Su nueva vida conlleva unas experiencias cercanas al delirio y una primera crisis de identidad ${ }^{6}$ :

Es ridículo. Estoy sentado en mi pequeña habitación, yo, Brigge, de veintiocho años y no conocido de nadie. Estoy aquí sentado, y no soy nada (p. 41).

Pero este horror abre su mente a la comprensión del mundo. Y a continuación lanza varias preguntas sobre la falsedad de la existencia, sobre la errónea concepción de la vida, del pasado y de Dios que normalmente se aceptan como verídicas, pero que él está dispuesto a desenmascarar:

¿Es posible que toda la historia del universo haya sido mal comprendida? [...] ¿Es posible que sea necesario recordar a cada uno que ha habido antepasados y que, por consiguiente, lleva en sí este pasado, y que no tiene nada que aprender de otros hombres que pretenden poseer un conocimiento mejor o diferente? (p. 42).

De este modo, Malte entiende que la incomprensión del presente radica en una concepción histórica y racional del pasado, una concepción falsa contra la que es necesario que él reaccione. Y así, el joven emprende una doble empresa: comenzar a escribir sin parar para aproximarse a su pasado y comprender su existencia. Y esta tarea conlleva un desdoblamiento de la personalidad del protagonista: un Yo que revive su infancia, y un Otro artista que dará testimonio de este pasado a través de la escritura; el primer Malte dice tengo miedo y el segundo dice aprendo a ver.

Así, por un lado, Malte se enfrenta al miedo refugiándose en su infancia, un tiempo superior al del adulto porque no hay límites en lo que es normal. Además, el mundo aristocrático danés, cercano al feudalismo, representa también un universo de individualismo y dignidad representado por la bella

\footnotetext{
${ }^{6}$ Citaré a partir de ahora Los cuadernos de Malte Laurids Brigge por la edición de F. Ayala (2003).
} 
muerte del Chambelán Brigge - ejemplo por antonomasia del concepto rilkeano de muerte individual - . Por otro lado, el Otro (el Yo artista) asume su tarea de recuperar el pasado, pero sin recurrir a una visión histórica, sino a una personal (la de su Yo inmerso en el pasado). Y así, dice en tercera persona pero refiriéndose a sí mismo:

Este Brigge, este extranjero, este joven insignificante, deberá sentarse y, en su quinto piso, deberá escribir, escribir día y noche. Sí, deberá escribir, y así acabará esa situación (p. 43).

\subsection{Vida y obra. El Yo y el Otro}

A partir de este momento exacto, Malte se sumerge inmediatamente en sus experiencias infantiles, en el castillo al que el conde Brahe se había retirado a declinar. La descripción de la casa y de sus familiares es incierta porque Malte renuncia a una reconstrucción objetiva, y por lo tanto falsa, de su infancia; prefiere reconstruir situaciones subjetivas que se anclaron caprichosamente en su espíritu ${ }^{7}$, y así incluso un fantasma (el de Cristina Brahe) alcanza a situarse entre la realidad de los vivos. Estas reminiscencias de un mundo aparentemente amenazante, lleno de gente extraña, muertos y aparecidos, aporta al joven una tranquilidad que se opone a la narración simultánea de sus experiencias parisinas: en su presente urbano el miedo invade a Malte a pesar de que nada le amenaza realmente. Esta enfermedad espiritual es vista casi con ironía en el pasaje del hospital, donde un médico puede explicar a Malte con sólo unas frases el doloroso proceso que tanto tiempo le costará superar al joven. En todo caso, la única salida de Malte a su agonía es la escritura del Otro, el Arte como salida del anonimato y forma de afrontar el mundo. Y, sin embargo:

Pero llegará el día en que mi mano estará distante, y cuando le ordene escribir, trazará palabras que yo no piense. Va a llegar el tiempo de la otra explicación, en el que las palabras se desatarán, en el que cada significado se deshará como una nube y caerá como el agua. [...]. Pero esta vez estaré escrito. Soy la impresión que va a transformarse. ¡Oh! Con un poco más podría

\footnotetext{
${ }^{7}$ El Otro artista de Malte va creando su subjetiva conciencia artística a raíz de lo que ve: «¿He dicho que este hombre era ciego? ¿No? Pues bien, era ciego. Era ciego y gritaba. Al decir esto lo falseo, escamoteo el carrito que empujaba; finjo no haberme dado cuenta de que voceaba coliflores. Pero ¿es esencial? Y aunque fuese esencial, ¿no importa más saber lo que he visto yo? He visto a un hombre viejo que era ciego y que gritaba. Eso es lo que he visto. Visto» (Rilke, 1910: 62).
} 
comprender todo y aprobar todo. Un paso solamente, y mi profunda miseria se transformará en felicidad. Pero ese paso, no puedo darlo; he caído y no puedo levantarme, porque estoy roto (p.68).

Malte trata de escribir el Yo que siente gracias al Otro que escribe, pero ¿puede el artista experimentar siempre la felicidad que siente cuando crea, cuando abandona la miseria de la realidad? En todo caso, el protagonista no consigue dar el último paso necesario, no consigue entender lo que le rodea, y ya no puede volver atrás; queda atrapado en un mundo que no es el del éxtasis artístico pero tampoco es el mundo real. Este fracaso por compatibilizar la vida y el arte, por captar globalmente un mundo lleno de correspondencias, es el fracaso al que Rilke se refería en una carta a Clara de 1907:

$Y$ de pronto (y por primera vez) comprendo el destino de Malte Laurids. ¿No es verdad que esta prueba era demasiado grande, que él no pudo pasarla en la realidad, aunque, a nivel de pensamiento, estaba convencido de su necesidad hasta el punto de buscarla, y durante tanto tiempo, que acabó por agarrarse a él para no soltarle ya nunca? El libro de Malte Laurids, si llega a escribirse alguna vez, no será más que el libro de este descubrimiento, por alguien que no estaba a su altura. Quizá incluso pasó la prueba: porque escribe la muerte del Chambelán; pero, como un Raskonikov, se quedó a medio camino, agotado por su acto, cesando de actuar en el mismo momento en que debía comenzar la acción, de manera que su libertad tan reciente se volvió contra él y como estaba sin defensas, le destrozó (Bermúdez Cañete, 1987: 91).

De nuevo, el Yo del joven deberá refugiarse en los recuerdos, pero esta vez enfocándolos más bien desde un punto de vista artístico. Como antes buscó muertes modélicas que le ayudaran a defenderse de la muerte serial que ve en la ciudad, ahora se inspira en artistas (Baudelaire, Beethoven, Ibsen, Flaubert) y en las mujeres que influyeron su infancia: Ingeborg, su madre y, sobre todo, su tía Abelone. En una escena fundamental de la novela, su malograda relación con esta última mujer es comparada a una tapicería que Malte ve en un museo. En el tapiz aparecen escenas en las que una dama y un unicornio simbolizan una historia de amor entre dos enamorados platónicos, una forma de amor que Rilke llama amor intransitivo y que se identifica con el Arte porque ambas experiencias son dos formas de autorrealización ${ }^{8}$. Y es que se-

\footnotetext{
8 «Siempre la amada supera al amado, porque la vida es más grande que el destino. El don de sí misma puede ser infinito; ésa es su felicidad. Pero la miseria sin nombre de su amor ha sido siempre ésta: que se le ha pedido limitar ese don» (Rilke, 1910: 205).
} 
gún la concepción rilkeana del amor, los grandes amantes de la historia, son los que guardan su amor para sí y renuncian a su amado. En este sentido, Malte observa a las jóvenes que ve pintando en un museo como chicas que, necesitando realizarse a sí mismas para crear sus propias identidades, abandonan el amor compartido, su familia y su religión para buscar su individualidad en los museos, es decir, en el Arte. Como ellas, Malte busca su identidad de artista, pero no llega a dar el paso definitivo que le libre de su miedo.

Pero la relación del protagonista con el arte, necesariamente impersonal, declina hasta que el protagonista acaba por identificarse con otros seres humanos. Por ejemplo, con su vecino Nicolaj Kusmitch, quien, como Malte, ha dejado que su imaginación le llevara demasiado lejos de la realidad y le ha reducido a la inacción (no puede salir de la cama porque el mismo movimiento de la Tierra le provoca náuseas). En cierto sentido, el delirante relato de la historia de Nicolaj le sirve a Malte para crearse su propio alter ego ${ }^{9}$, y también para poner en tercera persona su propia historia: su combate fracasado contra el miedo a vivir y a morir. Este irónico pasaje parece destruir la ilusoria personalidad de poeta que el joven se estaba construyendo en su escritura, y así, ya de vuelta al mundo exterior parisino, vuelve a sentir un pánico injustificado por los ruidos que provienen de la habitación de su vecino de piso.

Y puesto que el intento de Malte de curarse de su angustia refugiándose en la escritura de un pasado auténtico acaba por plantear más dudas, el joven se sumerge ahora en un pasado más remoto de la historia e incluso del mito en busca de modelos para sí mismo. Y lo que da pie a estas reflexiones es el recuerdo de un libro de estampas que parece tan ficticio como los míticos personajes de los que allí se hablaba: Carlos el Temerario y Gricha Otrepjov. La importancia de estos seres radica en que simbolizan un modo de vida y de muerte opuestos: el primero, fue siempre un prisionero de sí mismo, «aquel que durante toda su vida fue uno, el mismo, duro e inmutable como granito» (p. 191) e incapaz de trascenderse a sí mismo; pero, el segundo, no poseía una individualidad propia, por lo que era pura potencialidad para transformarse, e incluso en su muerte «hubo aún en él, infinitamente comprimidos, la voluntad y el poder de ser todo» (p. 191).

\footnotetext{
9 «Me acuerdo muy bien de esta historia porque me tranquilizó mucho. Puedo decir, incluso, que no he tenido nunca vecino tan agradable como ese Nicolaj Kusmitch, que seguramente me hubiese admirado, a mí también» (Rilke, 1910: 178).
} 
Y tras la obsesiva reflexión sobre la muerte que ha supuesto el texto hasta este punto, la aparición de Abelone va introduciendo, ya casi al final, el segundo eje temático fundamental de la obra: el amor (entendido como una forma de desprendimiento y no de posesión. Y precisamente la última parte del libro está llena de referencias a personajes históricos femeninos que Malte admira por haber sido capaces de amar de forma intransitiva: la monja Portuguesa, Eloísa, Gaspara Stampa, la condesa de Die, Clara d'Anduse, Louise Labbé, Marceline Desbordes, Elisa Mercoeur... han amado pero han renunciado a ser amadas para permanecer en soledad y desarrollar su individualidad. El mismo Malte cuenta cómo se produce su separación de Abelone tras una discusión ocasionada por la absoluta devoción que el joven ha empezado a experimentar por la lectura. Es decir, el amor debe dejar paso a la soledad, condición indispensable para el crecimiento personal, para convertirse en escritor y para que el pequeño Malte dejara de ser un niño:

Y si persistía en imaginar que mi infancia había pasado, en ese instante también todo el porvenir se había desvanecido, y no me quedaba exactamente más de lo que un soldado de plomo tiene bajo los pies para sostenerse.

Este descubrimiento me alejaba mucho más aún de los demás. Me absorbía en mí mismo y me llenaba de una especie de alegría definitiva, que yo tomaba por tristeza, porque sobrepasaba en mucho mi edad. [...] Y cuando volvi a Ulsgaard, y vi todos los libros, me arrojé sobre ellos, deprisa, casi con un sentimiento de culpabilidad (p. 199).

Este enriquecimiento personal basado en los libros, este encuentro de una conciencia personal gracias a la lectura (acto pasivo), es un preludio infantil de lo que el Malte adulto buscará en vano en la escritura (creación activa). Sin embargo, como se verá, el joven no estaba preparado para vivir sólo en el mundo de su Otro artista y, como el propio Rilke decía, «quedó a medio camino, agotado por su acto, cesando de actuar en el mismo momento en que debía comenzar la acción».

\subsection{Parábola sobre la vida y el arte}

Así, la revisión de la parábola del hijo pródigo que cierra el libro se puede interpretar como un asalto del Otro artista a la conciencia de Malte para contar en tercera persona una versión mítica de su vida, en la que se dan las claves de su fracaso por encontrar la salvación a través de la escritura. Rilke 
dice que esta parábola es la historia de aquel que no quiso ser amado, es decir, de aquel Malte niño que jugaba sin querer volver a casa, que odiaba los regalos mal adivinados de su familia y la máscara inmutable que le querían imponer los que le rodeaban:

Aún podían modificarse detalles; pero, en lo esencial, se era ya aquel por quien venían aquí; aquel al que habían compuesto desde hace tiempo una existencia hecha con su pequeño pasado y con sus propios deseos [...]. No está mal para ellos: se mantienen al contraluz y sólo sobre él cae con la luz la vergüenza de tener un rostro.

¿Permanecería y fingiría esta vida que le atribuían, y llegaría a parecérsele con todo el rostro? [...] No, se marchará(p. 246).

Así, el joven Malte huyó de su casa, de su familia, de su país, de su lengua y, sobre todo, del amor de los otros para buscar en su nueva libertad un rostro propio y mutable. Y para ello, decidió no amar nunca. Sin embargo, pronto comprendió que este proyecto era irrealizable y se rindió a las profundidades que le mostraban sus amantes, aunque esto le atara de nuevo al terror de ser correspondido:

¿Qué eran todas estas oscuridades al lado de la espesa tristeza de esos abrazos en los que se perdía todo? ¿No se despertaba uno con el sentimiento de carecer de futuro? ¿No iba uno de acá para allá sin sentido, sin tener derecho a ningún peligro? (p. 247).

Y de nuevo Malte emprendió una huida que él llama años de pastoreo en los que viajó y filosofó sobre cómo encontrar una explicación a la vida. Hasta que súbitamente encontró el camino del Arte, un torrente de inspiración, un sendero hacia Dios, en el que su Yo vivido y su Otro artista se separan más que nunca:

Es igual. Yo veo más que él, veo su existencia que comenzó entonces el largo camino hacia Dios, el largo trabajo silencioso y sin meta. Pues el que había querido contenerse para siempre, fue dominado una vez más por la necesidad íntima e incoercible de su corazón. Y esta vez esperaba ser escuchado (p. 248).

La búsqueda simbólica que emprende Malte, a raíz de su rapto de inspiración, le lleva a identificar al amor con el Arte y a éste con Dios: la escritura es su forma de acercarse a un amor perfecto y divino. Y es que su intento de llegar a Dios significa poder experimentar continuamente el éxtasis de la 
creación artística, es decir, del amor sobrehumano. Pero la inspiración que transporta la mente del joven poeta no dura lo suficiente, $\mathrm{y}$ ahora Malte, frustrado, debe soportar la impaciencia y trabajar la palabra como un artesano (exactamente lo que Rilke descubrió en París de la mano de Rodin):

Le aguardaba entonces el terror de percibir cuán difícil era: no quería creer, ante todo, que se pudiera emplear una vida entera en formar las estrofas de los primeros ejercicios, carentes de sentido. [...] Ahora que aprendía a amar con tanto trabajo y pena, comprendió cuán negligente y miserable había sido hasta entonces todo el amor que él creía prestar (p. 249).

Este momento vital se corresponde con la llegada del protagonista a París y con su descubrimiento de la escritura como forma de salvación. El nacimiento de su Otro artístico le proporcionará precisamente esa nueva visión del mundo que tan feliz le hará: la aceptación baudeleriana de todo lo real como fuente de creación: «... ahora incluso los placeres y el dolor necesarios perdían su regusto sazonado y se hacían para él puros y nutritivos» (p. 250). Y también en este momento se despierta en Malte el recuerdo de su infancia, que le parece inconclusa y un reflejo simétrico de lo que será su futuro. Por eso, porque los recuerdos de su niñez no le dejan avanzar hacia su futuro como artista, decide emprender un regreso a su vieja casa familiar en la que es recibido amorosamente por los suyos, a pesar de que a él no le importa mínimamente su amor egoísta.

Este regreso ha sido interpretado muchas veces de forma literal: como la vuelta de Malte a la casa de su familia en Dinamarca y, por lo tanto, como una capitulación; sin embargo, este regreso parece más bien simbólico, puesto que Malte ya no tiene familia ni casa a la que volver. Esta vuelta a la casa natal es en realidad una forma de referirse simbólicamente a la vuelta a la infancia que el protagonista ha experimentado a lo largo del libro. Y esta escena será también una confesión de que la búsqueda de su Dios a través de la escritura y a través de la vuelta al pasado ha fracasado, pero sólo por ahora. La conclusión del libro es que el intento del joven poeta de vivir en el mundo del espejo, en el mundo puro del arte, ha sido fallido; por ahora deberá conformarse con el grosero amor de los demás:

¿Qué sabían quién era él? Era ahora terriblemente difícil de amar, y sentía que sólo uno sería capaz de ello. Pero este aún no quería (p. 251).

Éste es el fracaso del que Rilke hablaba, no sólo de la imposibilidad de compaginar vida y arte, sino también del naufragio de Malte en su intento de 
superar su miedo a la vida gracias a la escritura: el camino del poeta es difícil y no hay vuelta atrás posible.

\section{CONCLUSIONES}

Este análisis de Los apuntes de Malte Laurids Brigge sólo es un precario acercamiento a una de las obras narrativas más complejas del siglo Xx, innovadora tanto en su forma como en su contenido. Por una parte, Rilke se adelantó varias décadas a la evolución natural de la novela europea al descentrar la narración tradicional, fragmentarla, abreviarla, mezclar géneros, renunciar a la biografía, a la caracterización social y a la representatividad de los personajes; todo ello para representar una vida de forma total, la simultaneidad del pasado y el presente, infancia y madurez. Esta obra pretende conseguir lo que no lograron los Nuevos poemas, unificar una amplia red de experiencias en una sola estructura, para simultanear diferentes periodos de tiempo en un instante de eternidad. La mezcla de diario y novela, autobiografía y ficción hizo que por mucho tiempo fuera difícil identificar al Malte como una novela, aunque, de hecho, podría decirse que es la primera obra de este género del siglo xx y que adelanta lo que luego será norma en Musil, Sartre o Joyce.

Por otra parte, también es revolucionaria la renuncia a un argumento tradicional a cambio de impresiones de carácter simbólico más propias de la poesía. Puesto que cada fragmento de la obra tiene su propio significado, es imposible trazar una evolución precisa de lo que ocurre. Sólo se intuye que, a través de diferentes fases de inmersión en el amor y en la muerte, Malte se va construyendo una identidad de poeta que, finalmente, no será suficiente para alcanzar la comprensión del mundo a través del arte entendido como amor.

La parábola del hijo pródigo que concluye la obra es una declaración sobre la evolución del joven poeta hasta la confesión de su fracaso final. Pero es importante señalar que este fracaso no sólo fue el de Malte, sino también fue el de Rilke, quien volvió a fallar en su intento de mostrar una vida compatible con el arte. Si se considera el Malte en relación con el resto de las obras de Rilke, se observará la importancia capital de esta novela para su autor: no sólo supuso una catarsis personal, sino también un paso fundamental hacia su verdadera obra maestra, las Elegías:

¿Y soy yo quien puede dar la explicación justa de las «Elegías»? Alcanzan infinitamente más allá de mí. Las considero una elaboración posterior de 
aquellas hipótesis esenciales que ya estaban dadas en el «Libro de horas», que en las dos partes de los «Nuevos poemas» utilizaron la imagen del mundo jugando y experimentando, y que después en el «Malte», reunidas en conflicto, repercutieron en la vida y casi llevaron a la demostración de que esta vida, colgada de tal manera sobre el vacío, es imposible. En las «Elegías», partiendo de los mismos presupuestos, la vida vuelve a ser posible, más aún, aquí experimenta esa definitiva «aprobación» a la que el joven Malte, aunque estuviera en el camino justo y difícil des longues études no podía llevar aún (Bermúdez Cañete, 1987: 183-188).

\section{REFERENCIAS BIBLIOGRÁFICAS}

Baudelaire, C. (1986). Pequeños poemas en prosa - Los paraísos artificiales. J. A. Millán Alba (ed.). Madrid: Cátedra [1869].

BeRmúdeZ-CAÑETE, F. (1987). Teoría poética . Rilke. Madrid: Júcar.

DÜRR, V. (1987). «Personal Identity and the Idea of the Novel: Hegel in Rilke». Comparative Literature 39, 97-114.

Holthusen, H. E. (1968). Rainer Maria Rilke: El poeta a través de sus propios textos. Madrid: Alianza Editorial.

Houe, P. (2004). «Vanishing Points, Turning Points, and Points of No Return: Geographies of Somewhere, Elsewhere, and Nowhere». Orbis Litterarum 59, 1-22.

JePHCOTt, E.F.N. (1972). Proust and Rilke: The Literature of Expanded Consciousness. Londres: Chatto \& Windus.

LORTHOLARY, B. (1993). «Le premier roman de notre siècle». Magazine Litteraire 308, 40-42.

Peters, G. (1992). «Autobiography as Masquerade: The Spectacle of Rilke's Other Self». Mosaic: A Journal for the Interdisciplinary Study of Literature 25. 1, 79-90.

RiLKe, R. M. (2003). Los apuntes de Malte Laurids Brigge, edición de F. Ayala. Oviedo: Editorial Losada [1910].

- (2000). Diarios de juventud. Valencia: Pre-Textos.

Zimmerman, U. (1993). «Malte Ludens: Humor, Satire, Irony, and Deeper Significance in Rilke's Novel». Germanic Review 68, 50-60. 